\title{
Clinical practice. Diagnosis and treatment of cow's milk allergy
}

\author{
C. M. Frank Kneepkens • Yolanda Meijer
}

Received: 10 February 2009 / Accepted: 18 February 2009/Published online: 7 March 2009

(C) The Author(s) 2009. This article is published with open access at Springerlink.com

\begin{abstract}
Introduction Cow's milk allergy (CMA) is thought to affect $2-3 \%$ of infants. The signs and symptoms are nonspecific and may be difficult to objectify, and as the diagnosis requires cow's milk elimination followed by challenge, often, children are considered cow's milk allergic without proven diagnosis. Diagnosis Because of the consequences, a correct diagnosis of CMA is pivotal. Open challenges tend to overestimate the number of children with CMA. The only reliable way to diagnose CMA is by double-blind, placebo-controlled challenge (DBPCFC).

Therapy At present, the only proven treatment consists of elimination of cow's milk protein from the child's diet and the introduction of formulas based on extensively hydrolysed whey protein or casein; amino acid-based formula is rarely indicated. The majority of children will regain tolerance to cow's milk within the first 5 years of life.

Conclusions Open challenges can be used to reject CMA, but for adequate diagnosis, DBPCFC is mandatory. In most children, CMA can be adequately treated with extensively hydrolysed whey protein or casein formulas.
\end{abstract}

Keywords Cow's milk allergy · Double-blind placebo-controlled food challenge - DBPCFC . Hypoallergenic formula

C. M. F. Kneepkens $(\bowtie)$

Department of Paediatrics, VU University Medical Centre, De Boelelaan 1117,

1081 HV Amsterdam, The Netherlands

e-mail: cmf.kneepkens@vumc.nl

Y. Meijer

Centre for Paediatric Allergology, Wilhelmina Children's

Hospital, University Medical Centre,

Utrecht, The Netherlands

e-mail: y.meijer@umcutrecht.nl

\section{Introduction}

The prevalence of cow's milk allergy (CMA) is estimated to be between $2 \%$ and $3 \%$ in infants and marginally lower in older children $[1,2]$. The percentage of parents that believe their child has CMA (or any other food allergy), however, amounts to between 5\% and 20\% [2-4]. Signs and symptoms of CMA are nonspecific and often difficult to objectify. Due to diagnostic burdens, the number of children treated for CMA is probably two to three times higher than justified [5]. A wrong diagnosis of CMA may not only result in somatisation but also in insufficient topical treatment of eczema, fear for or problems with the introduction of solids, and dietary deficiencies. Moreover, the long-term elimination of cow's milk protein (CMP) in a sensitised child without CMA may elicit severe adverse reactions when cow's milk is reintroduced [6]. Careful diagnosis of CMA, therefore, is of utmost importance.

\section{Definitions}

Adverse reactions to CMP can be present from birth, even in exclusively breast-fed infants. Not all reactions are of allergic nature. In 2001, the EAACI published a report on the terminology of adverse reactions [7]. The umbrella phrase, food hypersensitivity, covers non-allergic food hypersensitivity (traditionally named 'food intolerance') and allergic food hypersensitivity (food allergy). The latter requires an underlying immune mechanism. Most children with CMA have immunoglobulin E (IgE)-mediated allergy as a manifestation of their atopic constitution, with or without atopic eczema, asthma, or allergic rhinitis. A small group have cell-mediated allergy with gastro-intestinal symptoms [8]. 
History and physical investigation

Although signs and symptoms themselves (Table 1) cannot be used to diagnose CMA, history may be helpful as it can give clues to other diagnoses. Symptoms may start after the substitution of breast-feeding with formula feeding. The repeated occurrence of urticaria or rash shortly after CMP ingestion is suggestive of CMA. In general, signs and symptoms occurring late $(>2 \mathrm{~h})$ after the consumption of CMP are not caused by CMA [9]. Also, inconsistent signs and symptoms and those that do not emerge after every feeding must have a different aetiology.

The concurrent presence of other signs of atopy, such as eczema, wheezing, and asthma, increases the likelihood of CMA but cannot be used as a diagnostic proof. Especially the relation between CMA and eczema is difficult to assess. Although they can be present simultaneously and although CMP challenge may aggravate moderate to severe eczema in about $30 \%$ of cases [10-12], there is no proven relationship with mild eczema; moreover, there is no solid evidence that eczema can be expected to improve significantly on a CMP elimination diet [13]. Atopic eczema should be treated adequately with topical medication before CMA is considered [12]. Generally, other physical signs are lacking or nonspecific. Growth should be monitored closely.

Table 1 Signs and symptoms of CMA (those printed in italics are suggestive of severe allergy)

\begin{tabular}{ll}
\hline Gastrointestinal & Vomiting, regurgitation \\
& Abdominal pain \\
& Colic \\
& Diarrhoea \\
& Constipation \\
& Haemochezia \\
& Rash \\
Atopic eczema & Urticaria \\
Swin & Swollen lips \\
& Angio-oedema \\
& Pruritus \\
& Rhinitis \\
& Conjunctivitis \\
& Hoarseness, dysphagia \\
& Wheezing, asthma \\
& Food refusal \\
Respiratory & Growth retardation \\
& Iron-deficient anaemia \\
& Irritability, disturbed sleep \\
& Apnoea, apparent life-threatening events \\
& Anaphylaxis \\
\hline General &
\end{tabular}

Laboratory investigation

The role of laboratory tests in CMA diagnosis is debatable. The tests used in clinical practice only reveal sensitisation to CMP, which is not necessarily followed by clinically relevant allergy. Over $50 \%$ of sensitised children do not have food allergy [14-16]. In our experience, positive skin prick tests and allergen-specific IgE tests tend to be falsely interpreted as proof of CMA. This is not at all innocuous [6].

Although there is a strong positive correlation between the level of allergen-specific IgE and the chance of having CMA, unequivocally high specific IgE titres are rare and may occur in non-allergic children [17-19]. In general practice, therefore, laboratory tests are seldom helpful. The only way to prove CMA is through elimination and challenge.

\section{Cow's milk challenge}

After the elimination of CMP from the child's or the mother's diet, signs and symptoms should disappear within a few days. Atopic eczema, when caused by CMA, may take 4 weeks to improve sufficiently. Upon challenge, renewed confrontation with CMP results in recurrence of the presenting signs and symptoms.

Challenges may be performed either open or doubleblindly. With open challenges, both the staff performing the test and the parents know that the child is given CMP and in what amount. Double-blind placebocontrolled food challenges (DBPCFC) are designed to withhold this information both to the parents and the staff until afterwards. They are performed with placebo and verum in random order. CMP is concealed in a way that both test feedings look and taste similarly. DBPCFCs are superior to open challenges, but they are difficult to perform, require extensive preparation and are relatively expensive [9].

\section{Open challenge}

Open challenges can be used as the first diagnostic step. Challenges should follow an approved protocol, suited for the circumstances. In 1995, a national protocol for CMA diagnosis and treatment was introduced in Dutch well-baby clinics, including a simple open challenge, which is still in use [20]. After 2 weeks of elimination diet, the child ingests $10 \mathrm{ml}$ of original formula while being supervised for $1 \mathrm{~h}$; on the three following days, the formula is given in increasing amounts [20]. While originally, the protocol was developed to avoid inappropriate CMA diagnoses, presently, it is thought that it contrarily may induce falsely positive results and should 
be followed by DBPCFC. Preset conviction, subjective symptom appreciation and random symptom fluctuation increase the risk of falsely positive results. Between $27 \%$ and $70 \%$ of open-challenge CMA diagnoses are rejected after DBPCFC [21, 22].

Apart from this, a generally accepted open challenge procedure has only been published in 2007, when a European working group formulated a protocol for CMA diagnosis in general practice meant for children with relatively mild signs and symptoms [23]. The child's own formula is given in increasing amounts over $3 \mathrm{~h}$ (Table 2). In our opinion, however, open challenges should only be used to reject CMA $[1,10,12]$.

\section{DBPCFC}

Double-blind challenges are the gold standard. In 2007 as well, the Health Council of the Netherlands issued a report asking for the general introduction of DBPCFCs [1]. Dutch paediatric allergy centres and many hospitals already practice DBPCFCs [24-26]. They can be performed in well-baby clinics and general practices as well, as long as basic precautions have been met, including thorough knowledge of the procedure, careful patient selection and the equipment to block adverse reactions. The importance of DBPCFCs is underscored by the fact that between $13 \%$ and $30 \%$ of placebo tests are eliciting adverse reactions [24, 27]. There is no generally accepted protocol for DBPCFC. The protocol presented here is used in the Wilhelmina Children's Hospital [25].

Preparation The diet should be CMP free for at least 2 weeks. The patient's condition should be stable, especially concerning skin symptoms. Topical corticosteroids may be continued, but antihistamines should be discontinued at least one week in advance. Preparation includes a thorough history for previous adverse reactions.

Safety Tests should be performed in a day-care setting or during admission. Depending on the severity of previous signs and symptoms, a monitoring device and intravenous access may be needed. Clemastine and epinephrin for parenteral use must be at hand. The personnel should be well trained, also regarding the management of (rare) severe acute reactions.

Test material The child is given his/her own hypoallergenic formula or expressed breast milk. The research kitchen prepares coded bottles with (verum) or without (placebo) 5 g Protifar ${ }^{\circledR}$ powder (Nutricia/SHS), containing $4.4 \mathrm{~g}$ CMP, per $250 \mathrm{ml}$ formula.

Procedure Placebo and verum are administered on separate days, preferably 1 week apart. The test formula is given in increasing dosages at fixed intervals (Table 2) [26]. Adverse reactions are recorded. After a negative test, the child remains under supervision for $2 \mathrm{~h}$, after a positive test for $4 \mathrm{~h}$. The parents are asked to report late reactions. After the second test, a follow-up period of at least $48 \mathrm{~h}$ is observed before the seal is broken [26].

Evaluation The test is discontinued when the child experiences objective adverse reactions, subjective reactions that persist for $30 \mathrm{~min}$ or longer or repeated short-lived subjective reactions [9]. Allergic and non-allergic reactions are assessed separately and in the light of the child's history (Fig. 1). The final interpretation of the tests is given in Table 3. The DBPCFC is considered negative when verum did not elicit adverse reactions or when reactions following verum are not worse than following placebo. Even

Table 2 CMP administration schedules during challenge

\begin{tabular}{|c|c|c|c|c|c|c|}
\hline \multirow[t]{2}{*}{ Step } & \multicolumn{3}{|c|}{ Open challenge; child's own formula (Ref 34) } & \multicolumn{3}{|c|}{ DBPCFC; hypoallergenic formula, with $5 \mathrm{~g}$ of Protifar ${ }^{\circledR}(\operatorname{Ref} 28)$} \\
\hline & $\mathrm{T}(\min )$ & Dose $(\mathrm{ml})$ & $\mathrm{CMP}(\mathrm{mg})^{\mathrm{a}}$ & $\mathrm{T}(\min )$ & Dose (ml) & CMP (mg) \\
\hline 1 & 0 & Drop on lips & - & 0 & 0.1 & 2 \\
\hline 2 & 15 & 0.5 & 8 & 15 & 1 & 18 \\
\hline 3 & 45 & 1.0 & 15 & 30 & 10 & 176 \\
\hline 4 & 75 & 3.0 & 45 & 45 & 20 & 352 \\
\hline 5 & 105 & 10 & 150 & 60 & 30 & 528 \\
\hline 6 & 135 & 30 & 450 & 80 & 40 & 704 \\
\hline 7 & 165 & 50 & 750 & 110 & 60 & 1,056 \\
\hline 8 & 195 & 100 & 1,500 & 150 & 90 & 1,584 \\
\hline Total & & 195 & 2,925 & & 250 & 4,400 \\
\hline
\end{tabular}

${ }^{\mathrm{a}}$ Based on a mean protein content of $1.5 \mathrm{~g} / 100 \mathrm{ml}$; depending on brand, the protein content of infant formula is between $1.3 \mathrm{and} 1.6 \mathrm{~g} / 100 \mathrm{ml}$; of follow-on formula, 1.7 and $1.9 \mathrm{~g} / 100 \mathrm{ml}$ 


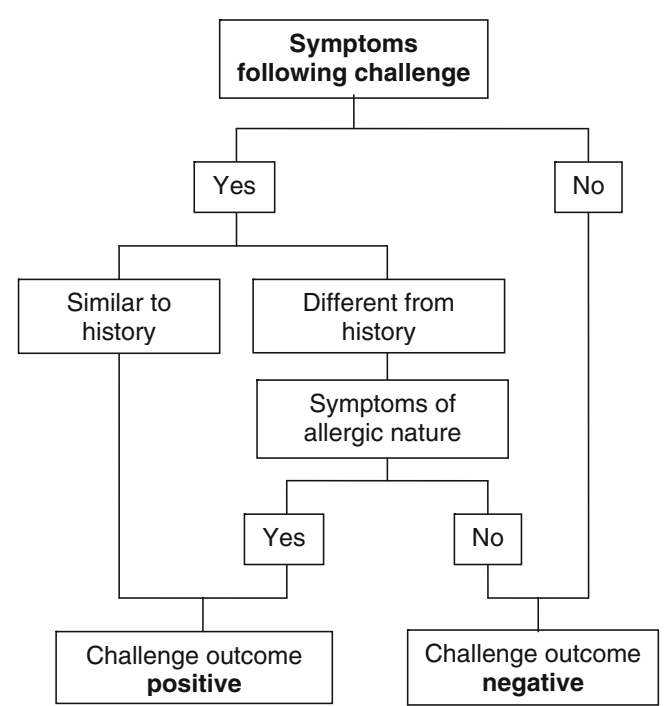

Fig. 1 Algorithm for the evaluation of the DBPCFC tests. The diagnosis of CMA can be derived from the combined results of both tests, placebo and verum (see Table 3). Adapted from 26

DBPCFCs, however, may not provide unequivocal results $[27,28]$.

\section{Risk assessment}

Although it is impossible to predict reaction severity during food challenges [29], some rules apply. Severe adverse reactions are more likely with previous severe reactions, with previous reactions on very low CMP doses, in older children, in children suffering from asthma and after prolonged exclusion of cow's milk [6,30,31].

Severe reactions with CMP challenges, however, are rare. During over 12 years of open challenges in Dutch well-baby clinics [20], no severe adverse events have been reported to the supervising committee (K.I. van Drongelen, Netherlands Nutrition Centre, personal communication) [20]. With the DBPCFC protocol presented here, over 500 challenges have been performed without any severe adverse events. Hence, CMP challenges can be

Table 3 Interpretation of DBPCFCs

\begin{tabular}{lll}
\hline Verum challenge & Placebo challenge & Test outcome \\
\hline Positive & Negative & Positive \\
Strongly positive & Positive & Positive \\
Positive & Positive & Negative \\
Negative & Negative & Negative \\
Positive & Strongly positive & Negative \\
\hline
\end{tabular}

Adapted from 26. safely performed in general practices, provided basic safety precautions are met. High-risk challenges should be performed in the hospital.

Cow's milk reintroduction

When CMA is refuted, standard formula and dairy products can safely be reintroduced in the diet of the child or the breast-feeding mother. Sometimes the child's illness has put so much strain on the parents that the help of a dietician is required to complete the transition to a normal diet. When, nevertheless, adverse reactions develop after reintroduction, this may be due to the natural course of the underlying condition (eczema), but often expresses the preset conviction of the parents that notwithstanding the test outcome, their child is suffering from CMA. These signs or symptoms are likely to disappear when the introduction is continued.

\section{Therapy}

Elimination of CMP from the diet is at present the only proven therapy.

Breast-fed infants Breast-feeding mothers need to eliminate all dairy products from their diets. There is controversy about other measures; as the child is at increased risk of other food allergies, it could be wise for her to eliminate allergens such as soy, egg and beef as well [8]. This increases the burden for the mother, however, and may provoke the failure of breast-feeding. A practical approach would be to start with CMP elimination and to eliminate other products only when the child remains symptomatic.

Bottle-fed infants Formula is replaced by hypoallergenic formula based on extensively hydrolysed CMP [32]. There is limited experience with hydrolysates from other sources, such as soy and collagen. The use of soy formula in infants $<6$ months is discouraged [23, 33]. The only formulas suitable for treatment are those that meet the criterium of being tolerated (with 95\% confidence interval) by at least $90 \%$ of patients with proven CMA [34]. The protein source may be based on extensively hydrolysed whey protein (eHW) or casein (eHC). Children that do not tolerate eHW may be able to tolerate eHC, and the other way round; despite differences in production and in vitro test results, there is no proven difference in clinical efficacy between both groups of formulas.

Some subgroups, including children with non-IgEmediated gastrointestinal CMA and severe atopic eczema, may show better results with amino-acid-based formulas as opposed to eHC or eHW [35]. Amino-acid-based formulas 
should be restricted to children who fail to tolerate extensively hydrolysed formulas.

Solids There is no need to postpone the introduction of solid foods or to follow a detailed introduction schedule. Most children can tolerate other (non-dairy) foods when introduced after the age of 4 months. In highly allergic children, solids are best introduced stepwise: only one or two new foods every 3 days. Because many parents are anxious to proceed with solid food introduction, dietary advice and guidance may be necessary.

Counselling The diagnosis of CMA has a great impact on the family. Proper education of parents and caretakers is essential. They need not only to learn avoidance strategies, such as reading food labels and avoiding high-risk situations, but also to recognise early signs and symptoms and to treat acute reactions. Antihistamines are prescribed for mild dermal conditions but will not suffice for severe systemic reactions. Anaphylactic reactions to CMP are rare; the parents of children with a history of anaphylaxis should be provided an epinephrine auto-injector and a written individualised treatment plan [36].

\section{Tolerance induction}

In the past decade, there is increasing interest in specific oral or sublingual immune therapy as a treatment option for CMA in older children [37, 38]. Immune therapy may lead to an increased tolerance threshold for CMP with persisting CMA [39] and may even induce permanent tolerance to CMP [37]. More research needs to be done before immune therapy can be offered as a competing therapeutic option.

\section{Prognosis}

CMA usually is a temporary condition. It is suggested that by the age of 3 years, $85 \%$ of children have regained tolerance to CMP [40]. More recent studies, however, are less optimistic; persisting IgE-mediated CMA is reported to persist up to the age of 8 years in $15 \%$ [41] to even $58 \%$ of children [42]. It is advisable to repeat challenges at regular intervals in order to keep the child on an elimination diet no longer than strictly necessary. There is no reason for DBPCFCs unless the diagnosis never has been made properly. Challenges can be scheduled at the ages of 12 , 18 and 24 months and yearly thereafter.

Conflict of interest The authors declare that they do have do conflict of interest and no financial relationships that might have influenced the present work.
Open Access This article is distributed under the terms of the Creative Commons Attribution Noncommercial License which permits any noncommercial use, distribution, and reproduction in any medium, provided the original author(s) and source are credited.

\section{References}

1. Health Council of the Netherlands (2007) Voedselallergie [Food allergy], publication 2007/07. Gezondheidsraad, Den Haag

2. Venter C, Pereira B, Voigt K et al (2008) Prevalence and cumulative incidence of food hypersensitivity in the first 3 years of life. Allergy 63:354-359. doi:10.1111/j.1398-9995.2007.01570.x

3. Venter C, Pereira B, Grundy J et al (2006) Incidence of parentally reported and clinically diagnosed food hypersensitivity in the first year of life. J Allergy Clin Immunol 117:1118-1124. doi:10.1016/ j.jaci.2005.12.1352

4. Young E, Stoneham MD, Petruckevitch A et al (1994) A population study of food intolerance. Lancet 343:1127-1130. doi:10.1016/S0140-6736(94) 90234-8

5. Pereira B, Venter C, Grundy J et al (2005) Prevalence of sensitization to food allergens, reported adverse reactions to foods, food avoidance and food hypersensitivity among teenagers. J Allergy Clin Immunol 11:884-892. doi:10.1016/j.jaci.2005.05.047

6. Flinterman AE, Knulst AC, Meijer Y et al (2006) Acute allergic reactions in children with AEDS after prolonged cow's milk elimination diets. Allergy 61:370-374. doi:10.1111/j.1398-9995. 2006.01018.x

7. Johansson SG, Hourihane JO, Bousquet J et al (2001) A revised nomenclature for allergy. An EAACI position statement from the EAACI nomenclature task force. Allergy 56:813-824. doi:10.1034/j.1398-9995.2001.t01-1-00001.x

8. Sampson HA (2004) Update on food allergy. J Allergy Clin Immunol 113:805-819. doi:10.1016/j.jaci.2004.03.014

9. Bindslev-Jensen C, Ballmer-Weber BK, Bengtsson U et al (2004) Standardization of food challenges in patients with immediate reactions to foods - position paper from the European Academy of Allergology and Clinical Immunology. Allergy 59:690-697. doi:10.1111/j.1398-9995.2004.00466.x

10. Breuer K, Heratizadeh A, Wulf A et al (2004) Late eczematous reactions to food in children with atopic dermatitis. Clin Exp Allergy 34:817-824. doi:10.1111/j.1365-2222.2004.1953.x

11. Eigenmann PA, Sicherer SH, Borkowski TA et al (1998) Prevalence of IgE-mediated food allergy among children with atopic dermatitis. Pediatrics 101:E8. doi:10.1542/peds.101.3.e8

12. Werfel T, Ballmer-Weber B, Eigenmann PA et al (2007) Eczematous reactions to food in atopic eczema: position paper of the EAACI and GA ${ }^{2}$ LEN. Allergy 62:723-728

13. Bath-Hextall F, Delamere FM, Williams HC (2008) Dietary exclusions for established atopic eczema. Cochrane Database Syst Rev (1):CD005203

14. Niggemann B, Rolinck-Werninghaus C, Mehl A et al (2005) Controlled oral food challenges in children - when indicated, when superfluous? Allergy 60:865-870. doi:10.1111/j.1398-9995. 2005.00828.x

15. Roberts S (2005) Challenging times for food allergy tests. Arch Dis Child 90:564-566. doi:10.1136/adc.2003.036814

16. Sampson HA (1999) Food allergy, part 2: Diagnosis and management. J Allergy Clin Immunol 103:981-989. doi:10.1016/S0091-6749(99) 70167-3

17. García-Ara C, Boyano-Martínez T, Díaz-Pena JM et al (2001) Specific IgE levels in the diagnosis of immediate hypersensitivity to cows' milk protein in the infant. J Allergy Clin Immunol 107:185-190. doi:10.1067/mai.2001.111592 
18. Sampson HA, Ho DG (1997) Relationship between food specific $\mathrm{IgE}$ concentrations and the risk of positive challenges in children and adolescents. J Allergy Clin Immunol 100:444-451. doi:10.1016/S0091-6749(97) 70133-7

19. van der Gugten AC, den Otter M, Meijer Y et al (2008) Usefulness of specific IgE in predicting cow's milk allergy. J Allergy Clin Immunol 121:531-533. doi:10.1016/j.jaci. 2007.10.042

20. Kneepkens CMF, Van Drongelen KI, Aarsen C (2005) Landelijke standaard voedselallergie bij zuigelingen [National standard for food allergy in infants], 5th edn. Voedingscentrum, Den Haag

21. Brouwer ML, Wolt-Plompen SA, Dubois AE et al (2006) No effects of probiotics on atopic dermatitis in infancy: a randomized placebo-controlled trial. Clin Exp Allergy 36:899-906. doi:10.1111/j.1365-2222.2006.02513.x

22. Venter C, Pereira B, Voigt K et al (2007) Comparison of open and double blind placebo controlled food challenges in diagnosis of food hypersensitivity amongst children. J Hum Nutr Diet 20:565579. doi:10.1111/j.1365-277X.2007.00828.x

23. Vandenplas Y, Koletzko S, Isolauri E et al (2007) Guidelines for the diagnosis and management of cow's milk protein allergy in infants. Arch Dis Child 92:902-908. doi:10.1136/adc. 2006.110999

24. Hospers IC, de Vries-Vrolijk K, Brand PL (2006) Dubbelblinde placebogecontroleerde koemelkprovocaties bij kinderen met een vermeende koemelkallergie, in een algemeen ziekenhuis: diagnose verworpen bij twee derde van de kinderen. [Double-blind, placebocontrolled cow's milk challenge in children with alleged cow's milk allergies, performed in a general hospital: diagnosis rejected in twothirds of the children]. Ned Tijdschr Geneeskd 150:1292-1297

25. Schade RP, Meijer Y, Pasmans SG et al (2002) Dubbelblinde placebogecontroleerde koemelkprovocatie voor de diagnostiek van koemelkallergie bij zuigelingen en kinderen. [Double blind placebo controlled cow's milk provocation for the diagnosis of cow's milk allergy in infants and children]. Ned Tijdschr Geneeskd 146:1739-1742

26. Vlieg-Boerstra BJ, Bijleveld CMA, van der Heide S et al (2004) Development and validation of challenge materials for double blind, placebo-controlled food challenges in children. J Allergy Clin Immunol 113:341-346. doi:10.1016/j.jaci.2003.10.039

27. Vlieg-Boerstra BJ, van der Heide S, Bijleveld CMA et al (2007) Placebo reactions in double-blind, placebo-controlled food challenges in children. Allergy 62:905-912. doi:10.1111/j.13989995.2007.01430.x

28. Niggemann B, Beyer K (2007) Pitfalls in double-blind, placebocontrolled oral food challenges. Allergy 62:729-732. doi:10.1111/ j.1398-9995.2006.01282.x

29. Clark AT, Ewan PW (2003) Interpretation of tests for nut allergy in one thousand patients in relation to allergy or tolerance. Clin
Exp Allergy 330:1041-1045. doi:10.1046/j.1365-2745. 2003.01624.x

30. Bock SA, Muñoz-Furlong A, Sampson HA (2007) Further fatalities due to anaphylactic reactions to foods. J Allergy Clin Immunol 119:1016-1018. doi:10.1016/j.jaci.2006.12.622

31. Sampson HA, Mendelson L, Rosen JP (1992) Fatal and near fatal anaphylactic reactions to food in children and adolescents. N Engl J Med 327:380-384

32. Høst A, Halken S (2004) Hypoallergenic formulas - when, to whom and how long: after 15 years we know the right indication!. Allergy 59(suppl 78):45-52. doi:10.1111/j.1398-9995. 2004.00574.x

33. Turck D (2007) Soy protein for infant feeding: what do we know? Curr Opin Clin Nutr Metab Care 10:360-365. doi:10.1097/ MCO.0b013e3280fa821b

34. American Academy of Pediatrics Committee on Nutrition (2000) Hypoallergenic infant formulas. Pediatrics 106:346-349. doi: $10.1542 /$ peds. 106.2 .346

35. Hill DJ, Murch SH, Rafferty K et al (2007) The efficacy of amino acid-based formulas in relieving the symptoms of cow's milk allergy: a systematic review. Clin Exp Allergy 37:808-822. doi:10.1111/j.1365-2222.2007.02724.x

36. Muñoz-Furlong AM (2003) Daily coping strategies for patients and their families. Pediatrics 111:1654-1661

37. Longo G, Barbi E, Berti I et al (2008) Specific oral tolerance induction in children with very severe cow's milk induced reactions. J Allergy Clin Immunol 121:343-347. doi:10.1016/j. jaci.2007.10.029

38. Staden U, Rolinck-Werninghaus C, Brewe F et al (2007) Specific oral tolerance induction in food allergy in children: efficacy and clinical patterns of reaction. Allergy 62:1261-1269. doi:10.1111/ j.1398-9995.2007.01501.x

39. Skripak JM, Nash SD, Rowley H et al (2008) A randomized, double-blind placebo-controlled study of milk oral immunotherapy for cow's milk allergy. J Allergy Clin Immunol 122:1154-1160. doi:10.1016/j.jaci.2008.09.030

40. Høst A, Halken S (1990) A prospective study of cow milk allergy in Danish infants during the first 3 years of life. Clinical course in relation to clinical and immunological type of hypersensitivity reaction. Allergy 45:587-596. doi:10.1111/j.1398-9995.1990. tb00944.x

41. Saarinen KM, Pelkonen AS, Mäkelä MJ, Savilahti E (2005) Clinical course and prognosis of cow's milk allergy are dependent on milk-specific IgE status. J Allergy Clin Immunol 116:869-875. doi:10.1016/j.jaci.2005.06.018

42. Skripak JM, Matsui EC, Mudd K, Wood RA (2007) The natural history of IgE-mediated cow's milk allergy. J Allergy Clin Immunol 120:1172-1177. doi:10.1016/j.jaci.2007.08.023 